\title{
Ureia de liberação lenta em substituição ao farelo de soja na terminação de bovinos confinados
}

\author{
Henrique de Oliveira Azevedo(1), Fabiano Alvim Barbosa(1), Décio Souza Graça(1), \\ Pedro Veiga Rodrigues Paulino ${ }^{(2)}$, Rafahel Carvalho Souza ${ }^{(3)}$, Thiago José Piron Lavall ${ }^{(3)}$ e Filipe Lage Bicalho(1) \\ (1)Universidade Federal de Minas Gerais, Escola de Veterinária, Avenida Antônio Carlos, no 6.627, Caixa Postal 567, Campus Pampulha, \\ CEP 30161-970 Belo Horizonte, MG, Brasil. E-mail: henriquezvedo@hotmail.com, fabianoalvimvet@hotmail.com, decio@vet.ufmg.br, \\ filipelagebicalho@yahoo.com.br (2)Nutron Alimentos, Avenida Dr. José Bonifácio C. Nogueira, o 150, Galleria Plaza, Salas 601-602, \\ CEP 13091-611 Campinas, SP, Brasil. E-mail: pedro_paulino@cargill.com ${ }^{(3)}$ Pontifícia Universidade Católica de Minas Gerais, Rua do \\ Rosário, no 1.081, Bairro Angola, CEP 32604-115 Betim, MG, Brasil. E-mail: rsouza.vet@gmail.com, lavallvet@gmail.com
}

\begin{abstract}
Resumo - O objetivo deste trabalho foi avaliar o efeito da substituição da proteína bruta do farelo de soja pela ureia de liberação lenta sobre o desempenho, as características de carcaça e o custo alimentar de bovinos Nelore terminados em confinamento. Foram utilizados 48 machos inteiros da raça Nelore, com idade média de 22 meses e peso inicial de $367,95 \pm 18,52 \mathrm{~kg}$. Utilizou-se o delineamento inteiramente casualizado com quatro tratamentos: FS, 8,91\% de farelo de soja e $0 \%$ de ureia de liberação lenta (ULL); OP33, 6,01\% de farelo de soja e $0,46 \%$ de ULL; OP $67,2,94 \%$ de farelo de soja e $0,94 \%$ de ULL; e OP $100,0 \%$ de farelo de soja e $1,41 \%$ de ULL. Não houve diferença entre os tratamentos para as variáveis peso inicial, peso final, ganho médio diário, ganho de carcaça, consumo de matéria seca, conversão alimentar, eficiência biológica, peso de carcaça quente, rendimento de carcaça e custo alimentar da arroba produzida. A ureia de liberação lenta, usada em substituição parcial ou total à proteína do farelo de soja na dieta, não altera o desempenho, as características de carcaça e a eficiência econômica de bovinos de corte confinados.
\end{abstract}

Termos para indexação: ganho de peso vivo, nitrogênio não proteico, proteína degradável no rúmen, ureia protegida.

\section{Slow-release urea to replace soybean meal in finishing feedlot cattle}

\begin{abstract}
The objective of this work was to evaluate the effect of replacing crude protein of soybean meal by slow-release urea on the performance, carcass traits, and feeding costs of feedlot Nelore steers. Forty-eight Nelore steers were used, with an average age of 22 months and weight of $367.95 \pm 18.52 \mathrm{~kg}$. A completely randomized design was used with four treatments: SM, 8.91\% soybean meal and $0 \%$ slow-release urea (SRU); OP33, 6.01\% soybean meal and $0.46 \%$ SRU; OP67, 2.94\% soybean meal and $0.94 \%$ SRU; and OP $100,0 \%$ soybean meal and $1.41 \%$ SRU. No difference was observed between treatments for the variables initial weight, final weight, average daily gain, carcass gain, dry matter intake, feed conversion, biological efficiency, hot carcass weight, carcass yield, and feed cost of produced arroba. Slow-release urea, used to partially or totally replace protein of soybean meal in the diet, does not modify the performance, carcass traits, and economic efficiency of feedlot cattle.
\end{abstract}

Index terms: live weight gain, non-protein nitrogen, rumen degradable protein, protected urea.

\section{Introdução}

A terminação de bovinos em confinamento já foi estratégia para o aproveitamento das características sazonais do mercado, que permitiam altas rentabilidades, em razão das diferenças de preço do boi gordo entre a safra e a entressafra. Nas décadas anteriores, essas rentabilidades ultrapassavam $40 \%$, mas, atualmente, não passam de $20 \%$. O confinamento deve, então, ser encarado como uma estratégia para: aumentar a escala de produção da propriedade (arrobas produzidas por hectare por ano); retirar a categoria de engorda das pastagens na seca, para permitir a entrada dos animais de recria; e produzir novilhos precoces e, também, animais com carcaça mais pesada e com, no mínimo, 3,0 $\mathrm{mm}$ de gordura de cobertura (gordura de acabamento na décima segunda costela), exigidos pelos frigoríficos (Ferreira et al., 2006).

O farelo de soja, por apresentar proteína de alto valor biológico, é um dos alimentos proteicos mais fornecidos aos animais. Porém, por se tratar de um insumo largamente utilizado nas produções de aves 
e suínos, seu preço sofre variação de acordo com os períodos de safra e entressafra e com as demandas do mercado internacional. Portanto, a inclusão desse ingrediente pode resultar em aumento no custo da dieta, sobretudo quando o preço de mercado atinge altas cotações. Dessa forma, a substituição de fontes de proteína verdadeira por compostos nitrogenados não proteicos (NNP) é uma alternativa para redução nos custos de produção (Paixão et al., 2006), uma vez que são mais viáveis economicamente $(\mathrm{R} \$$ por $\mathrm{kg}$ de proteína), ao se considerar a mesma quantidade de nitrogênio.

A amônia gerada a partir de NNP é o principal composto utilizado pelos microrganismos ruminais, principalmente bactérias fermentadoras de carboidratos, como fonte de nitrogênio para a síntese de proteína microbiana (Stewart et al., 1997). A proteína microbiana pode suprir de 50 a $100 \%$ da proteína metabolizável exigida para bovinos de corte, e é considerada fonte de boa qualidade quanto à digestibilidade intestinal (em torno de $80 \%$ ) e ao perfil em aminoácidos (Nutrient..., 2000).

Apesar dos benefícios relacionados à utilização da ureia como fonte de NNP, Azevedo et al. (2008) apontam que, quando os níveis de amônia absorvidos pelo rúmen superam a capacidade do fígado de biotransformá-la em ureia, há acúmulo de amônia na corrente sanguínea, o que causa intoxicação e pode levar à morte do animal. Desse modo, a alta taxa de hidrólise ruminal, associada à necessidade de adaptação dos bovinos à ureia, tem impulsionado o desenvolvimento de produtos com a premissa de liberação lenta e constante, que possam promover sincronização da liberação de NNP com a degradação de carboidratos.

Experimentos com ureia de liberação lenta (polimerizada) mostram que a hidrólise ruminal desse produto é cadenciada e favorece o sincronismo entre a degradação da fibra e a liberação de nitrogênio para bactérias fibrolíticas (Ribeiro et al., 2011; Benedeti et al., 2014). Nesse sentido, sua utilização na dieta de bovinos de corte confinados deve, primeiramente, atender às exigências dos microrganismos ruminais, já que há estreita relação entre a eficiência da atividade microbiana e o desempenho produtivo dos animais. Esses fatores impactam diretamente a rentabilidade financeira do sistema, que não deve focar apenas no custo da dieta mas, também, na influência da manipulação dos fatores nutricionais sobre as características de carcaça.

De acordo com Lopes et al. (2012), parte da comercialização da carne inspecionada no Brasil é realizada com base nas características de carcaça, e há entraves comerciais na indústria de carne bovina, tanto no Brasil como no mundo, relacionados à falta de uniformidade em idade de abate dos animais, cobertura de gordura, marmorização da carne e rendimento de cortes nobres. Assim, entre as estratégias para resolver esses entraves na cadeia mercadológica, destacamse o confinamento de bovinos de corte e a busca por alimentos que possam proporcionar maior peso de carcaça, com acabamento de gordura adequada.

O objetivo deste trabalho foi avaliar o efeito da substituição da proteína bruta do farelo de soja pela ureia de liberação lenta sobre o desempenho, as características de carcaça e o custo alimentar de bovinos Nelore terminados em confinamento.

\section{Materiais e Métodos}

O estudo foi realizado no confinamento experimental da Pontifícia Universidade Católica, no município de Esmeraldas, MG $\left(19^{\circ} 48^{\prime} \mathrm{S}, 44^{\circ} 11^{\prime} \mathrm{W}\right)$, no período de julho a novembro de 2012. Foram utilizados 48 bovinos Nelore inteiros de 22 meses de idade, com peso vivo inicial de $367,95 \pm 18,52 \mathrm{~kg}$. Os animais (três por baia) foram alojados em 16 baias coletivas de $90 \mathrm{~m}^{2}$ cada uma $(3,0 \times 30 \mathrm{~m})$, em que tinham acesso livre ao bebedouro e ao comedouro, ambos revestidos de concreto.

Inicialmente, os animais foram pesados, identificados, vermifugados e vacinados. Posteriormente, foram submetidos a um período, de 24 dias, de adaptação ao confinamento, no qual receberam $1,8 \%$ do peso vivo em matéria seca da dieta total, composta por bagaço de cana triturada como fonte de volumoso, além de ração concentrada à base de milho, caroço de algodão, polpa cítrica, farelo de soja, ureia e minerais. Foram utilizadas proporções de volumoso:concentrado, com base na matéria seca total, de 60:40 no período inicial e de 40:60 no período final da adaptação.

$\mathrm{Na}$ fase experimental, os animais foram distribuídos em quatro tratamentos, com 0, 33, 67 e 100\% de substituição do farelo de soja pela ureia de liberação lenta (ULL) (Optigen II, Alltech, Nicholasville, KY, EUA), em base de proteína bruta. Os tratamentos 
foram: FS, 8,91\% de farelo de soja e $0 \%$ de ULL; OP $33,6,01 \%$ de farelo de soja e $0,46 \%$ de ULL; OP 67 , $2,94 \%$ de farelo de soja e $0,94 \%$ de ULL; e OP 100 , $0 \%$ de farelo de soja e 1,41\% de ULL. As dietas foram formuladas para serem isoenergéticas e isoproteicas (Tabela 1).

Durante a fase experimental, os animais foram confinados por um período de 98 dias, em que os alimentos foram fornecidos na proporção de 20:80 (volumoso:concentrado), quatro vezes ao dia, e ajustados em intervalos de 3 dias, para permitir sobras em torno de 5 a $10 \%$ do ofertado.

Utilizou-se o delineamento experimental inteiramente casualizado, com: 12 repetições (animais) por tratamento, para as variáveis peso inicial, peso final, ganho médio diário, ganho de peso de carcaça, peso de carcaça quente e rendimento de carcaça; e 4 repetições (baias) por tratamento, para as variáveis consumo de matéria seca, conversão alimentar, eficiência biológica e custo alimentar da arroba produzida.

As amostras de sobras foram agrupadas de forma proporcional com base em seus respectivos teores de matéria seca, o que resultou em amostras compostas de períodos de 3 semanas cada um; essas amostras foram pré-secas em estufa ventilada, a $55^{\circ} \mathrm{C}$ por 72 horas, e, em seguida, moídas em moinho tipo Wiley com peneira de crivos de 2,0 mm. As amostras da dieta total fornecida e das sobras foram avaliadas quanto aos teores de matéria seca (MS), pelo método 934.01; proteína bruta (PB), pelo método 984.13; extrato etéreo (EE), pelo método 920.85; e cinzas, pelo método 938.08, de acordo com a AOAC International (1990). A matéria orgânica (MO) foi calculada como a diferença entre a MS e as cinzas, em que a matéria mineral era equivalente às cinzas. Para a análise da fibra em detergente neutro corrigida para cinzas e proteína (FDNcp), as amostras foram tratadas com alfa amilase termoestável e corrigidas para cinzas (Mertens, 2002) e para compostos nitrogenados (Licitra et al., 1996).

O conteúdo dietético de carboidratos não fibrosos (CNF) e nutrientes digestíveis totais (NDT) foi quantificado por meio das equações propostas por Detmann \& Valadares Filho (2010): $\mathrm{CNF}=\mathrm{MO}$ ((PB - PB derivada da ureia $+\%$ da ureia $)+$ FDNcp + EE) e NDT $=$ PBvd + CNFvd + FDNd $+2,25$ EEvd - FMndt, em que PBvd, CNFvd, FDNd, EEvd e FMndt

Tabela 1. Proporção dos ingredientes com base na matéria seca total, preço em $\mathrm{R} \$$ por kg de matéria natural dos ingredientes e composição nutricional com base na percentagem de matéria seca das dietas experimentais.

\begin{tabular}{|c|c|c|c|c|c|}
\hline \multirow[t]{2}{*}{ Ingrediente (\%) } & \multicolumn{4}{|c|}{ Tratamento $^{(1)}$} & \multirow[t]{2}{*}{$\mathrm{R} \$$ por $\mathrm{kg}$} \\
\hline & FS & OP33 & OP67 & OP100 & \\
\hline Bagaço de cana & 20,00 & 20,00 & 20,00 & 20,00 & 0,11 \\
\hline Polpa cítrica & 14,14 & 14,14 & 14,14 & 14,14 & 0,37 \\
\hline Ureia & 0,42 & 0,42 & 0,42 & 0,42 & 1,56 \\
\hline Milho moído & 39,65 & 42,09 & 44,68 & 47,15 & 0,45 \\
\hline Caroço de algodão & 14,00 & 14,00 & 14,00 & 14,00 & 0,55 \\
\hline Farelo de soja & 8,91 & 6,01 & 2,94 & 0,00 & 0,92 \\
\hline Ureia de liberação lenta & 0,00 & 0,46 & 0,94 & 1,41 & 3,00 \\
\hline Sulfato de amônio & 0,05 & 0,05 & 0,05 & 0,05 & 0,98 \\
\hline Mistura mineral & 2,83 & 2,83 & 2,83 & 2,83 & 1,49 \\
\hline \multirow[t]{2}{*}{ Total $(\%)$} & 100 & 100 & 100 & 100 & - \\
\hline & \multicolumn{5}{|c|}{ Composição nutricional (\%) } \\
\hline Matéria seca & 83,45 & 83,52 & 83,22 & 83,73 & - \\
\hline Nutrientes digestíveis totais (NDT) & 73,96 & 74,30 & 75,88 & 76,93 & - \\
\hline Proteína bruta $(\mathrm{PB})$ & 12,91 & 12,74 & 13,5 & 13,63 & - \\
\hline Extrato etéreo & 3,74 & 3,91 & 3,7 & 3,87 & - \\
\hline $\mathrm{FDNcp}^{(2)}$ & 30,99 & 31,21 & 30,72 & 30,63 & - \\
\hline Carboidratos não fibrosos & 47,64 & 47,65 & 49,16 & 49,76 & - \\
\hline $\operatorname{PDR}^{(3)}(\%$ de NDT $)$ & 12,00 & 12,16 & 12,24 & 12,44 & - \\
\hline $\operatorname{PDR}^{(3)}(\%$ de $\mathrm{PB})$ & 67,95 & 70,94 & 68,80 & 70,21 & - \\
\hline
\end{tabular}

${ }^{(1)} \mathrm{FS}, \mathrm{OP} 33$, OP67 e OP100 equivalem, respectivamente, a 0,33, 67 e 100\% de substituição da proteína proveniente do farelo de soja pela ureia de liberação lenta. ${ }^{(2)} \mathrm{FDNcp}$, fibra em detergente neutro corrigida para cinzas e proteína. ${ }^{(3)} \mathrm{PDR}$, proteína degradável no rúmen estimada pelos dados fornecidos pelas Tabelas Brasileiras de Composição de Alimentos para Bovinos (Valadares Filho et al., 2008. CQBAL 3.0). 
são, respectivamente, proteína bruta verdadeiramente digestível, carboidratos não fibrosos verdadeiramente digestíveis, fibra em detergente neutro digestível, extrato etéreo digestível e contribuição metabólica fecal, com FMndt $=\mathrm{PB}+\mathrm{CNF}+2,25 \mathrm{EE}$.

Os animais foram pesados em regime de jejum de líquidos e sólidos de 16 horas nos dias 0,46 e 98 da fase experimental. Foram coletados os dados de peso vivo inicial (PI), peso vivo final (PF) e ganho médio diário (GMD). $\mathrm{O}$ consumo médio diário de matéria seca, expresso em quilos de matéria seca (CMS) e em percentagem do peso vivo (CMS\%PV), foi mensurado pela diferença entre a quantidade de sobras e a quantidade total fornecida das dietas no dia anterior, em quilos de matéria seca. A conversão alimentar foi determinada pela razão entre CMS e GMD. Já a eficiência biológica foi obtida pela razão entre o consumo de MS total no período experimental e o ganho de peso em quilos de carcaça. Tendo como base o preço de mercado dos insumos utilizados na formulação das dietas no início do experimento, o custo alimentar da arroba de carcaça produzida foi calculado pela razão entre os custos totais referentes à alimentação e as arrobas ganhas durante o período experimental.

A análise de sensibilidade do custo da arroba produzida foi realizada por meio de variações no preço do farelo de soja, tendo-se mantido as demais condições constantes (ceteris paribus) e utilizado, como base, os dados de desempenho dos animais obtidos no experimento. Após a análise de sensibilidade, as médias dos tratamentos foram comparadas pelo teste de Tukey, a 5\% de probabilidade, para identificar, a partir de que preço, a utilização da ureia de liberação lenta se tornaria economicamente viável em relação ao farelo de soja.

Todos os procedimentos realizados no presente trabalho foram aprovados pelo Comitê de Ética em Experimentação Animal, sob o protocolo Cetea $n^{-}$ 200/2012. Os animais foram abatidos em frigorífico comercial, de acordo com os procedimentos humanitários, como exigido pela legislação brasileira. No frigorífico, foram obtidos: peso de carcaça quente (PCQ) e rendimento de carcaça (RC), em que $\mathrm{RC}(\%)=(\mathrm{PCQ} / \mathrm{PF}) 100$; e ganho de peso de carcaça $($ G.CAR $)$, em que G.CAR $=(P F \times \mathrm{RC})-(\mathrm{PI} \times 50 \%)$.

$\mathrm{A}$ análise estatística dos dados foi realizada com auxílio do programa estatístico SAS (SAS Institute,
Cary, NC, EUA), e, para a comparação múltipla entre as médias dos tratamentos, adotou-se o teste de Tukey, a $5 \%$ de probabilidade.

\section{Resultados e Discussão}

Não houve efeito no consumo médio diário de matéria seca, tanto para CMS quanto para $\mathrm{CMS} \% \mathrm{PV}$, quando o farelo de soja foi substituído pela ULL na dieta. Resultado similar também foi observado para GMD. Provavelmente, a proteína microbiana proveniente dos NNP fornecida pela ULL tenha sido capaz de suprir as exigências de proteína metabolizável dos animais em terminação, uma vez que todas as dietas forneceram o mínimo de $12 \%$ de proteína degradável no rúmen (PDR), em relação ao nutriente digestível total (NDT), recomendados por Valadares Filho et al. (2006). Outro fator que deve ser considerado é que os tratamentos apresentavam um mínimo de $65 \%$ da PB da dieta total provenientes de fontes de proteína vegetal de boa qualidade, o que pode ter influenciado de forma positiva o balanço entre PB e NDT e, consequentemente, os resultados obtidos.

Os resultados encontrados para CMS foram semelhantes $(p>0,05)$ entre os tratamentos (Tabela 2$)$, uma vez que os valores nutricionais das dietas foram próximos (Tabela 1), o que ocasionou consumos médios similares de NDT, PB e PDR, que apresentaram médias de 7,34, 1,29 e 0,90 kg por animal por dia, respectivamente. Com consumos de nutrientes semelhantes $(p>0,05)$, os resultados de desempenho e características de carcaça não foram alterados pelos diferentes tratamentos. Segundo Pereira et al. (2008), isso pode ser explicado pelo fato de o GMD e a deposição de carcaça serem afetados pelos nutrientes ingeridos e pelo balanço entre estes.

Benedeti et al. (2014) observaram efeito linear decrescente $(\mathrm{p}<0,10)$ sobre $\mathrm{CMS}$, ao avaliar a influência da substituição de 0, 33, 66 e 100\% da PB do farelo de soja por ULL, em dietas de terminação de bovinos de corte. Conforme os autores, a alta digestibilidade do milho utilizado na formulação das dietas, a elevada superfície específica do alimento e a oferta da dieta apenas uma vez ao dia podem ter ampliado a disponibilidade de metabolitos energéticos, o que não seria acompanhado pela assimilação de nitrogênio no rúmen, que, teoricamente, seria liberado gradativamente pela ULL. 
O ruminante requer dois tipos de proteína: uma fonte de proteína degradável, para síntese de proteína microbiana; e uma fonte de proteína não degradável, para ser digerida diretamente no abomaso e no intestino (Bach et al., 2005). Para maximizar a eficiência da fermentação microbiana, o requerimento de proteína degradada no rúmen para crescimento microbiano, logicamente, deve ser suprido anteriormente à proteína não degradável no rúmen (Klopfenstein, 1996). A PDR foi adequada em todos os tratamentos, pois estes forneceram o mínimo de $12 \%$ de PDR, em relação ao NDT (Tabela 1), indicados por Valadares Filho et al. (2006).

Oliveira Junior et al. (2006), ao avaliar a substituição da fonte de proteína verdadeira (farelo de soja) por ureia ou amireia em dietas de alto concentrado (80\%), relataram menor CMS $(\mathrm{p}<0,05)$ na dieta com apenas farelo de soja, deficiente em proteína degradada no rúmen. Os resultados encontrados por estes autores reforçam a justificativa de menor consumo alimentar em dietas deficientes em proteína degradada no rúmen. Entretanto, isso não foi observado no presente trabalho, em que todas as dietas supriram as exigências de PDR e não houve diferença entre os valores de CMS ( $p>0,05)$. Bourg et al. (2012) obtiveram resultados semelhantes aos do presente trabalho, ao utilizar ULL em três dietas para novilhos Angus mestiços, com diferentes fontes de proteína; contudo, estes autores não constataram diferenças $(p>0,10)$ para GMD, PF e CMS.
Mandarino et al. (2013) avaliaram bovinos Nelore e Nelore $\times$ Brahman submetidos a três diferentes tratamentos, com dietas de alto concentrado: $25 \%$ de silagem de milho $+75 \%$ de concentrado; exclusiva de pellets; e $85 \%$ de milho grão inteiro $+15 \%$ de pellets. Os autores obtiveram valor semelhante aos do presente trabalho para CMS $(9,75 \mathrm{~kg}$ por dia), porém um valor menor para CMS\%PV $(1,99)$, uma vez que os animais apresentaram maior PF $(493,32 \mathrm{~kg})$. Sartor Neto et al. (2011), ao avaliar bovinos Nelore inteiros que receberam dietas com alto teor de concentrado $(87 \%$ na MS) e bagaço de cana como fonte de volumoso, com variação apenas no nível de inclusão de tanino $(0$, 0,2 e $0,4 \%$ na MS), relataram valor médio de $2,26 \%$ para $\mathrm{CMS} \% \mathrm{PV}$, muito próximo à média de $2,31 \%$ encontrada no presente trabalho.

A substituição da proteína bruta do farelo de soja pela ULL não influenciou a conversão alimentar, a qual representa a eficiência com que o animal transforma o alimento em peso vivo (Tabela 2). Em estudo realizado com novilhos Nelore inteiros terminados em confinamento, que receberam dietas com diferentes níveis de concentrado (20, 40, 60 e $80 \%$ da MS total) e dois níveis de proteína (16 e 18\% na MS), Silva et al. (2002) encontram valor de conversão alimentar de 9,91, para os animais que receberam a dieta com $80 \%$ de concentrado, valor maior que o obtido no presente trabalho. Já Rubiano et al. (2009) obtiveram menor valor para conversão alimentar $(6,90)$, ao

Tabela 2. Valores médios de desempenho animal, custo da dieta em matéria natural ( $\mathrm{R} \$$ por $\mathrm{kg}$ de $\mathrm{MN}$ ) e custo alimentar da arroba de carcaça produzida (custo de arroba) no confinamento, em função dos diferentes tratamentos ${ }^{(1)}$.

\begin{tabular}{|c|c|c|c|c|c|c|c|}
\hline \multirow[t]{2}{*}{ Variável(2) } & \multicolumn{4}{|c|}{ Tratamento $^{(3)}$} & \multirow[t]{2}{*}{ Média geral } & \multirow[t]{2}{*}{$\mathrm{EPM}^{(4)}$} & \multirow[t]{2}{*}{$\mathrm{p}(>\mathrm{F})$} \\
\hline & $\mathrm{FS}$ & OP33 & OP67 & OP100 & & & \\
\hline Peso inicial (kg) & 371,08 & 368,00 & 364,58 & 368,17 & 367,96 & 2,74 & 0,8714 \\
\hline Peso final (kg) & 478,83 & 481,67 & 472,17 & 475,33 & 477,00 & 4,53 & 0,8900 \\
\hline GMD (kg) & 1,10 & 1,16 & 1,10 & 1,09 & 1,11 & 0,03 & 0,8785 \\
\hline GCAR (arroba) & 4,89 & 5,21 & 5,44 & 5,18 & 5,18 & 0,14 & 0,6141 \\
\hline CMS (kg por dia) & 9,83 & 9,99 & 9,56 & 9,73 & 9,78 & 0,19 & 0,8806 \\
\hline CMS (\%PV) & 2,31 & 2,35 & 2,28 & 2,30 & 2,31 & 0,03 & 0,8963 \\
\hline $\mathrm{CA}(\mathrm{kg})$ & 9,00 & 8,64 & 8,73 & 8,90 & 8,82 & 0,16 & 0,8436 \\
\hline $\mathrm{EB}(\mathrm{kg})$ & 197,44 & 188,98 & 172,71 & 184,02 & 185,79 & 3,08 & 0,0846 \\
\hline PCQ (kg) & 258,96 & 262,21 & 263,83 & 261,71 & 261,68 & 2,66 & 0,9325 \\
\hline $\mathrm{RC}(\%)$ & 54,11 & 54,45 & 55,89 & 55,04 & 54,87 & 0,24 & 0,0613 \\
\hline $\mathrm{R} \$$ por $\mathrm{kg}$ de $\mathrm{MN}^{(5)}$ & 0,42 & 0,43 & 0,43 & 0,42 & - & - & - \\
\hline Custo de arroba $(\mathrm{R} \$)$ & 102,22 & 98,09 & 90,10 & 93,96 & 96,09 & 1,62 & 0,1013 \\
\hline
\end{tabular}

${ }^{(1)}$ Letras diferentes na mesma linha diferem significativamente pelo teste Tukey, a 5\% de probabilidade. ${ }^{(2)} \mathrm{GMD}$, ganho médio diário; GCAR, ganho de peso de carcaça; CMS, consumo de matéria seca; CA, conversão alimentar; EB, eficiência biológica; PCQ, peso de carcaça quente; e RC, rendimento de carcaça. ${ }^{(3)} \mathrm{FS}$, OP33, OP67 e OP100 equivalem, respectivamente, a 0, 33, 67 e 100\% de substituição da proteína proveniente do farelo de soja pela ureia de liberação lenta. ${ }^{(4)} \mathrm{EPM}$, erro-padrão da média. ${ }^{(5)}$ Os valores de custo da dieta (R\$ por kg de MN) não apresentam comparação estatística. 
avaliar novilhos Nelore que receberam dietas com alto teor de volumoso (mínimo de 50\% na MS total). Essa divergência entre os resultados não é comum na literatura, em que a conversão alimentar apresenta resposta linear decrescente à medida que se aumenta o teor de concentrado na MS total da dieta (Costa et al., 2005), que melhora a eficiência de alimentação dos animais pelas maiores densidade energética e concentração de nutrientes (Missio et al. 2010).

A eficiência biológica não apresentou diferença entre os tratamentos (Tabela 2). Esta eficiência, também conhecida como "eficiência de deposição de carcaça", relaciona a quantidade de matéria seca ingerida com as arrobas ganhas no confinamento. Na prática, almejamse valores de eficiência biológica que variam entre 120 e $150 \mathrm{~kg}$ de MS por arroba produzida, valores inferiores aos do presente trabalho. Isso significa que as dietas avaliadas não proporcionaram eficiência adequada na deposição de carcaça, possivelmente em razão do GMD inferior a 1,2 $\mathrm{kg}$ por bovino por dia. Paulino et al. (2008), ao avaliar o desempenho de bovinos Nelore de três classes sexuais (inteiros, castrados e fêmeas), encontraram valores de eficiência biológica de $198 \mathrm{~kg}$ de MS por arroba (ou 13,20 kg de MS por kg de carcaça) para machos inteiros, valor superior à média de $185,79 \mathrm{~kg}$ de MS por arroba obtida no presente trabalho. Desse modo, a eficiência biológica pode variar de acordo com a dieta e a classe sexual.

O PF, o GMD, o PCQ e o RC foram semelhantes entre os tratamentos, sem efeito da inclusão de ULL na dieta, com médias de $477 \mathrm{~kg}, 1,11 \mathrm{~kg}, 261,68 \mathrm{~kg}$ e $54,87 \%$, respectivamente. Esses indicadores de desempenho sofrem influência direta da ingestão de energia e proteína da dieta, que foi similar, o que corrobora os resultados de Pinos-Rodríguez et al. (2010).

O valores médios de PCQ obtidos no presente trabalho estão próximos dos relatados por Oliveira et al. (2009), com média de 262,05 kg para Nelore confinados. Já as médias de RC encontram-se na amplitude observada na literatura, de 53 a $58 \%$, como em Rubiano et al. (2009), que relataram média de 55\% para animais jovens, e em Leme et al. (2003) e Ezequiel et al. (2006), que observaram valores de 54 a 58,3\% com a utilização de dietas de alto teor de concentrado, contendo bagaço de cana como fonte de volumoso, na terminação de bovinos Nelore em confinamento.
Os valores de custo de arroba produzida não diferiram entre os tratamentos, com média de $\mathrm{R} \$ 96,02$ (Tabela 2). A análise de sensibilidade mostrou que o uso da ULL foi viável economicamente quando o preço do farelo de soja atingiu o valor de $\mathrm{R} \$ 1,09$ por $\mathrm{kg}$, aproximadamente $36,3 \%$ do preço desse tipo de ureia. $\mathrm{O}$ uso da ULL pode ocasionar ganhos indiretos para o produtor, como na logística e no armazenamento dos insumos, uma vez que, em condições como as avaliadas no presente trabalho, 1,0 Mg de ULL pode substituir até $6,0 \mathrm{Mg}$ de farelo de soja.

\section{Conclusão}

A ureia de liberação lenta, usada em substituição parcial ou total à proteína bruta do farelo de soja na dieta de bovinos Nelore confinados, não altera o desempenho, o rendimento de carcaça e o custo da arroba produzida.

\section{Agracecimentos}

À Coordenação de Aperfeiçoamento de Pessoal de Nível Superior (Capes), pela concessão de bolsa e à Alltech, pelo apoio financiero.

\section{Referências}

AOAC INTERNATIONAL. Official methods of analysis of the AOAC International. $15^{\text {th }}$ ed. Arlington: AOAC International, 1990.

AZEVEDO, E.B. de; PATIÑO, H.O.; SILVEIRA, A.L.F. da; LÓPEZ, J.; BRÜNING, G.; KOZLOSKI, G.V. Incorporação de ureia encapsulada em suplementos proteicos fornecidos para novilhos alimentados com feno de baixa qualidade. Ciência Rural, v.38, p.1381-1387, 2008. DOI: 10.1590/S0103-84782008000500029.

BACH, A.; CALSAMIGLIA, S.; STERN, M.D. Nitrogen metabolism in the rumen. Journal of Dairy Science, v.88, p.E9-E21, 2005. Supplement. DOI: 10.3168/jds.S0022-0302(05)73133-7.

BENEDETI, P.D.B.; PAULINO, P.V.R.; MARCONDES, M.I.; VALADARES FILHO, S.C.; MARTINS, T.S.; LISBOA, E.F.; SILVA, L.H.P.; TEIXEIRA, C.R.V.; DUARTE, M.S. Soybean meal replaced by slow release urea in finishing diets for beef cattle. Livestock Science, v.165, p.51-60, 2014. DOI: 10.1016/j. livsci.2014.04.027.

BOURG, B.M.; TEDESCHI, L.O.; WICKERSHAM, T.A.; TRICARICO, J.M. Effects of a slow-release urea product on performance, carcass characteristics, and nitrogen balance of steers fed steam-flaked corn. Journal of Animal Science, v.90, p.3914-3923, 2012. DOI: 10.2527/jas.2011-4832.

COSTA, M.A.L.; VALADARES FILHO, S. de C.; PAULINO, M.F.; VALADARES, R.F.D.; CECON, P.R.; PAULINO, P.V.R.; 
MORAES, E.H.B.K. de; MAGALHÃES, K.A. Desempenho, digestibilidade e características de carcaça de novilhos zebuínos alimentados com dietas contendo diferentes níveis de concentrado. Revista Brasileira de Zootecnia, v.34, p.268-279, 2005. DOI: 10.1590/S1516-35982005000100031.

DETMANN, E.; VALADARES FILHO, S.C. On the estimation of non-fibrous carbohydrates in feeds and diets. Arquivo Brasileiro de Medicina Veterinária e Zootecnia, v.62, p.980-984, 2010. DOI: $10.1590 / \mathrm{S} 0102-09352010000400030$.

EZEQUIEL, J.M.B.; GALATI, R.L.; MENDES, A.R.; FATURI, C. Desempenho e características de carcaça de bovinos Nelore em confinamento alimentados com bagaço de cana-de-açúcar e diferentes fontes energéticas. Revista Brasileira de Zootecnia, v.35, p.2050-2057, 2006. DOI: 10.1590/S1516-35982006000700024.

FERREIRA, J.J.; BRONDANI, I.L.; LEITE, D.T.; RESTLE, J.; ALVES FILHO, D.C.; MISSIO, R.L.; HECK, I.; SEGABINAZZI, L.R. Características da carcaça de tourinhos Charolês e mestiços Charolês $\mathrm{x}$ Nelore terminados em confinamento. Ciência Rural, v.36, p.191-196, 2006. DOI: 10.1590/S0103-84782006000100029.

KLOPFENSTEIN, T. Need for escape protein by grazing cattle. Animal Feed Science and Technology, v.60, p.191-199, 1996. DOI: 10.1016/0377-8401(96)00977-7.

LEME, P.R.; SILVA, S. da L.; PEREIRA, A.S.C.; PUTRINO, S.M.; LANNA, D.P.D.; NOGUEIRA FILHO, J.C.M. Utilização do bagaço de cana-de-açúcar em dietas com elevada proporção de concentrados para novilhos Nelore em confinamento. Revista Brasileira de Zootecnia, v.32, p.1786-1791, 2003. DOI: 10.1590/ S1516-35982003000700029.

LICITRA, G.; HERNANDEZ, T.M.; VAN SOEST, P.J. Standardization of procedures for nitrogen fractionation of ruminant feeds. Animal Feed Science and Technology, v.57, p.347-358, 1996. DOI: 10.1016/0377-8401(95)00837-3.

LOPES, L.S.; LADEIRA, M.M.; MACHADO NETO, O.R.; PAULINO, P.V.R.; CHIZZOTTI, M.L.; RAMOS, E.M.; OLIVEIRA, D.M. de. Características de carcaça e cortes comerciais de tourinhos Red Norte e Nelore terminados em confinamento. Revista Brasileira de Zootecnia, v.41, p.970-977, 2012. DOI: 10.1590/S1516-35982012000400020.

MANDARINO, R.A.; BARBOSA, F.A.; CABRAL FILHO, S.L.S.; LOBO, C.F.; SILVA, I.S.; OLIVEIRA, R.V.; DIOGO, J.M.S.; GUIMARÃES JÚNIOR, R. Desempenho produtivo e econômico do confinamento de bovinos zebuínos alimentados com três dietas de alto concentrado. Arquivo Brasileiro de Medicina Veterinária e Zootecnia, v.65, p.1463-1471, 2013. DOI: 10.1590/ S0102-09352013000500027.

MERTENS, D.R. Gravimetric determination of amylase-treated neutral detergent fiber in feeds with refluxing in beakers or crucibles: collaborative study. Journal of AOAC International, v.85, p.1217-1240, 2002.

MISSIO, R.L.; BRONDANI, I.L.; ALVES FILHO, D.C.; SILVEIRA, M.F. da; FREITAS, L. da S.; RESTLE, J. Comportamento ingestivo de tourinhos terminados em confinamento, alimentados com diferentes níveis de concentrado na dieta. Revista Brasileira de Zootecnia, v.39, p.1571-1578, 2010. DOI: $10.1590 / \mathrm{S} 1516-35982010000700025$.

NUTRIENT requirements of beef cattle. $7^{\text {th }}$ ed. Washington: National Academy, 2000. 242p.

OLIVEIRA JUNIOR, R.C. de; PIRES, A.V.; FERNANDES, J.J. de R.; SANTOS, F.A.P.; SUSIN, I.; ARAUJO, R.C. de. Efeitos de fontes nitrogenadas, em dietas com alto teor de concentrado para bovinos de corte, sobre o consumo de matéria seca, digestibilidade e degradabilidade dos nutrientes. Ciência Animal Brasileira, v.7, p.207-216, 2006.

OLIVEIRA, E.A. de; SAMPAIO, A.A.M.; FERNANDES, A.R.M.; HENRIQUE, W.; OLIVEIRA, R.V.; RIBEIRO, G.M. Desempenho e características de carcaça de tourinhos Nelore e Canchim terminados em confinamento recebendo dietas com cana-de-açúcar e dois níveis de concentrado. Revista Brasileira de Zootecnia, v.38, p.2465-2472, 2009. DOI: 10.1590/S1516-35982009001200024.

PAIXÃO, M.L.; VALADARES FILHO, S. de C.; LEÃO, M.I.; VALADARES, R.F.D.; PAULINO, M.F.; MARCONDES, M.I.; FONSECA, M.A.; SILVA, P.A.; PINA, D. dos S. Ureia em dietas para bovinos: consumo, digestibilidade aparente, ganho de peso, característica de carcaça e produção microbiana. Revista Brasileira de Zootecnia, v.35, p.2451-2460, 2006. DOI: 10.1590/ S1516-35982006000800035.

PAULINO, P.V.R.; VALADARES FILHO, S. de C.; DETMANN, E.; VALADARES, R.F.D.; FONSECA, M.A.; VÉRAS, R.M.L.; OLIVEIRA, D.M. Desempenho produtivo de bovinos Nelore de diferentes classes sexuais alimentados com dietas contendo dois níveis de oferta de concentrado. Revista Brasileira de Zootecnia, v.3,p.1079-1087,2008. DOI: 10.1590/S1516-35982008000600019.

PEREIRA, O.G.; SOUZA, V.G.; VALADARES FILHO, S.C.; PEREIRA, D.H.; RIBEIRO, K.G.; CECON, P.R. Consumo e digestibilidade dos nutrientes e desempenho de bovinos de corte recebendo dietas com diferentes níveis de ureia. Ciência Animal Brasileira, v.9, p.552-562, 2008.

PINOS-RODRÍGUEZ, J.M.; PEÑA, L.Y.; GONZÁLEZ-MUÑOZ, S.S.; BÁRCENA, R.; SALEM, A. Effects of a slow-release coated urea product on growth performance and ruminal fermentation in beef steers. Italian Journal of Animal Science, v.9, p. 16-19, 2010.

RIBEIRO, S.S.; VASCONCELOS, J.T.; MORAIS, M.G.; ÍTAVO, C.B.C.F.; FRANCO, G.L. Effects of ruminal infusion of a slow-release polymer-coated urea or conventional urea on apparent nutrient digestibility, in situ degradability, and rumen parameters in cattle fed low-quality hay. Animal Feed Science and Technology, v.164, p.53-61, 2011. DOI: 10.1016/j.anifeedsci.2010.12.003.

RUBIANO, G.A.G.; ARRIGONI, M. de B.; MARTINS, C.L.; RODRIGUES, É.; GONÇALVES, H.C.; ANGERAMI, C.N. Desempenho, características de carcaça e qualidade da carne de bovinos superprecoces das raças Canchim, Nelore e seus mestiços. Revista Brasileira de Zootecnia, v.38, p.2490-2498, 2009. DOI: 10.1590/S1516-35982009001200027.

SARTOR NETO, A.; RIBEIRO, E.L. de A.; MIZUBUTI, I.Y.; PEREIRA, E.S.; CUNHA, G.E.; SILVA, L. das D.F. da; BARBOSA, M.A.A. de F.; BUMBIERIS JUNIOR, V.H. Desempenho e características de carcaça de bovinos Nelore confinados recebendo dietas de alto teor de concentrado com diferentes níveis de tanino.

Pesq. agropec. bras., Brasília, v.50, n.11, p.1079-1086, nov. 2015 DOI: 10.1590/S0100-204X2015001100011 
Semina: Ciências Agrárias, v.32, p.1179-1190, 2011. DOI: 10.5433/1679-0359.2011v32n3p1179.

SILVA, F.F. da; VALADARES FILHO, S. de C.; ÍTAVO, L.C.V.; VELOSO, C.M.; PAULINO, M.F.; CECON, P.R.; SILVA, P.A.; GALVÃO, R.M. Desempenho produtivo de novilhos Nelore, na recria e na engorda, recebendo dietas com diferentes níveis de concentrado e proteína. Revista Brasileira de Zootecnia, v.31, p.492-502, 2002. DOI: 10.1590/S1516-35982002000200026.

STEWART, C.S.; FLINT, H.J.; BRYANT, M.P. The rumen bacteria. In: HOBSON, P.N.; STEWART, C.S. (Ed.). The rumen microbial ecosystem. London: Chapman \& Hall, 1997. p.10-72. DOI: 10.1007/978-94-009-1453-7_2.
VALADARES FILHO, S.C.; MACHADO, P.A.S.; CHIZZOTTI, M.L.; AMARAL, H.F.; MAGALHÃES, K.A.; ROCHA JUNIOR, V.R.; CAPELLE, E.R. CQBAL 3.0: tabelas brasileiras de composição de alimentos para bovinos. Viçosa: Universidade Federal de Viçosa, Departamento de Zootecnia, 2008. Disponível em: <http://www.ufv.br/cqbal>. Acesso em: 29 out. 2013.

VALADARES FILHO, S.C.; PINA, D.S.; CHIZZOTTI, M.L.; VALADARES, R.F.D. Degradação ruminal da proteína dos alimentos e síntese de proteína microbiana. In: VALADARES FILHO, S.C.; PAULINO, P.V.R.; MAGALHÃES, K.A. (Ed.). Exigências nutricionais de zebuínos e tabelas de composição de alimentos BR-Corte. Viçosa: Ed. da UFV, 2006. p.13-46.

$\overline{\text { Recebido em } 9 \text { de julho de } 2015 \text { e aprovado em } 8 \text { de setembro de } 2015}$ 